\title{
Analysis on Parking Sharing Choice Behavior of Urban Residents
}

\author{
Han Xue ${ }^{1, a, *}$, Zhang Dongdong ${ }^{2, b}$, and Wang $\mathrm{Di}^{1, \mathrm{c}}$ \\ ${ }^{1}$ Hohai University Wentian College, Manshan Anhui 243031, China \\ ${ }^{2}$ Nanjing Forestry University, Nanjing Jiangsu 210037, China \\ ahanxue_echo@163.com, ${ }^{b} 304731496 @ q q . c o m,{ }^{c} 113177620 @ q q . c o m$
}

Keywords: Parking shared space, Logit model, parking choice, urban parking

\begin{abstract}
The emergence of shared parking spaces provides a new idea to solve the problem of urban parking, and "parking space sharing" has gradually become the research focus of experts and scholars at home and abroad. In order to further study the choices of shared parking spaces by urban residents, this paper makes a quantitative analysis of the influencing factors of the choices of parking spaces and builds a Logit model for discrete choices of shared spaces. The model test shows that parking rate, walking distance after parking, parking information, and convenience of parking lots exert a significant impact on parking decisions.
\end{abstract}

\section{Introduction}

The difficulty of urban parking has always been a major problem affecting the development of urban traffic. With the growth of retention rate of small cars in recent years, the contradiction between supply and demand of parking spaces has become increasingly serious. Parking space sharing $^{[1]}$ is a means of enabling adjacent land users to share parking spaces so as to reduce the total number of parking spaces for land users, that is, it uses different time and space distributions of parking demands of adjacent plots of different land types to realize the sharing of parking spaces and solve the problem of unbalanced supply and demand of parking spaces. Since shared parking is characterized by superior parking supply capacity, saving parking space and improving revenue of parking spaces, it has become an important means to alleviate the parking problems of urban residents in Beijing, Shanghai, Qingdao and other cities.

Scholars at home and abroad have analyzed and studied the applicability of shared parking spaces and the behaviors of residents' parking space sharing. Lalani ${ }^{[2]}$ discussed the applicability of shared parking spaces. Research shows that parking space sharing be implemented in cinemas, shopping malls, hotels and other places. Iman ${ }^{[3]}$ analyzed the spatial distribution of shared parking spaces by building a SPATT model. Ran ${ }^{[4]}$ established a bi-level decision-making model for parking space sharing with the average satisfaction of parkers as the objective function. Pan ${ }^{[5]}$ analyzed parking behaviors of residents in Dalian City, due to different travel purposes, there exist relatively great differences in parking places and parking time of residents as well. Guan ${ }^{[6]}$ et al. concluded that the purposes of travel, the payers of parking fees, the genders and occupations of parkers have a great effect on the decision-making of parking. Zong ${ }^{[7]}$ et al. analyzed the impact of 
parking rates, types of parking lots and parking duration on residents' parking choices in detail, and built a Bayesian network model. $\mathrm{Mo}^{[8]}$ et al. analyzed the parking behaviors of Shanghai residents, and considered that when a person pays parking fees, he will be more sensitive to parking costs. At present, domestic and foreign researches on parking space sharing mainly focus on the applicability, implementation model and implementation steps of parking space sharing, etc., while there is still relatively lack of quantitative analysis of the open periods of shared parking spaces and the corresponding open quantities in different periods. And in respect of parking space sharing, the research on parkers' parking behaviors and the analysis of influencing factors of parking sharing behaviors is still in its infancy. Therefore, this paper mainly analyzes the influencing factors of parking behaviors under the mode conditions of parking space sharing, and forecasts the demanded quantity of shared parking spaces, thus providing a theoretical basis for the study of the quantity of shared parking spaces opened to the outside in urban residential areas.

\section{Analysis on Influencing Factors of Residents' Choices of Shared Parking Space}

Whether the policy of parking space sharing can be successfully implemented depends mainly on the degree of acceptance of shared parking spaces by urban residents. Studying residents' behaviours of choosing shared parking spaces and analysing the factors that affect their behaviour choices exert a positive effect on the reasonable opening of the number of shared parking spaces and the determination of parking rates.

\subsection{Parking Rates.}

Parking rate is one of the most important factors affecting parking behaviors ${ }^{[9]}$. When the parkers pays the parking fees, the parker shows higher sensitivity to the parking rate. The adjustment of parking supply and demand relation can be realized by adjusting parking rate.

Parking charges for shared parking spaces directly determine residents' use of shared parking spaces. If parking fees for shared spaces in all regions follow the same rate, there is no obvious difference in residents' parking selection process; If all regions adopt differentiated charging policies for shared spaces, the demand for parking selection of high-priced shared spaces will be inhibited; If the encouraging charging policy for shared parking spaces is adopted, that is, parking fees are determined according to changes in the time distribution of parking demand for shared spaces in various regions, high fees are charged during peak periods of parking demand for shared spaces, and low fees are collected during idle periods of shared spaces, thus increasing the utilization rates of shared parking spaces.

\subsection{Walking Distance after Parking.}

Walking distance after parking is one of the priority issues for parkers. The shorter the walking distance after parking, the better the convenience of parking spaces. The influence of walking distance should also be taken into consideration in the design of shared parking spaces. If the walking distance is too long, it will also lead to new parking problems. Residents' acceptance of the length of walking distance after parking is closely related to the parking time, and the longer the parking time is, the longer the walking distance travelers can accept. Research shows that $95 \%$ of the residents in large and medium-sized cities can accept about 220m walking distance. If the walking distance exceeds $350 \mathrm{~m}$, the service level of parking spaces is relatively lower ${ }^{[10]}$.

Studies have shown that parkers sometimes use walking distance to exchange parking fees, that is, parkers will park their vehicles in parking lots that are far from the destinations but require lower parking rates. Thus, regulators can make use of the leverage of parking price to adjust the 
concentration index of parking lots in different areas, charge higher parking fees in the parking lots in urban centers, and apply lower parking rates to the parking lots in surrounding areas of the city, thereby forming differentiated parking charges.

\subsection{Parking Information.}

According to the survey, more than $85 \%$ of respondents hope to get information about parking spaces before parking. In terms of shared parking spaces, parking guidance information has a more significant impact on parking behaviors of residents. The shared parking spaces publish relevant space information through mobile phone APP, citizen information system and other platforms so that users can realize space inquiry, reservation, payment and other operations through the network platform.

\subsection{Convenience of Parking Lots.}

Convenience of parking lots mainly includes the difficulty of vehicles arriving at parking spaces, that is, the congestion of roads; waiting time for entering the garage and waiting time for picking up cars after arriving at the parking lot. In general, the residents generally desire to choose the parking lot with short waiting time for entering the garage and convenient car taking. Therefore, it is required that the parking lot of shared spaces should have a relatively perfect parking lot management system to facilitate vehicle access and enhance the convenience of the parking lot of shared spaces.

\subsection{Other Factors.}

The choice behaviors of shared parking spaces will also be influenced by factors such as parker's characteristics, parking lot characteristics and vehicle characteristics.

Parker's characteristics mainly include the parker's gender, age, occupation, income level; parking lot characteristics mainly refer to parking lot size, structure, parking mode, whether safe or not; vehicle characteristics mainly include private cars and official vehicles.

The purpose of parking is also an important factor that affects the choice of travel. Usually, parkers who go on official traveling are mostly time-sensitive, that is, they pay more attention to walking distance after parking and reaching their travel destination quickly; parkers who visit relatives and friends are mostly price-sensitive, that is, they pay more attention to the economy and convenience of parking facilities; while those who aim at leisure tourism are more concerned about the comfort, safety and service level of the parking lot. In addition, residents' acceptance of shared parking spaces will also produce a direct impact on their choice behaviors. During the development of shared parking spaces, residents still have some doubts about their safety and convenience, and hold a wait-and-see attitude toward shared parking spaces. To this end, government departments and parking lot managers should improve the management level of shared parking spaces, and appropriately take preferential parking measures to enhance residents' acceptance of parking space sharing.

\section{Logit Model for Discrete Choices}

Logit model for discrete choices is a disaggregate model based on the principle of maximizing the utility of travelers ${ }^{[11]}$, which can establish the utility function of all sorts of parking facilities by the sensitivity of parking lot users to the characteristics of parking lots ${ }^{[12]}$ : 


$$
U_{\text {in }}=V_{\text {in }}+\varepsilon_{\text {in }}
$$

Wherein, $U_{i n}$ represents the utility function of the n parking space user's choosing the plan $i$, $V_{\text {in }}$ is the fixed term and $\varepsilon_{\text {in }}$ is the probability term.

Based on the utility maximization theory, the formula (2) can be used to represent the probability $P_{i n}$ of the $n$ parking space user's choosing the plan $i$ :

$$
\begin{aligned}
P_{i n} & =\operatorname{Prob}\left(U_{i n}>U_{j n} ; i \neq j, j \in A_{n}\right) \\
& =\operatorname{Prob}\left(V_{i n}+\varepsilon_{i n}>V_{j n}+\varepsilon_{j n} ; i \neq j, j \in A_{n}\right) \\
A_{n} & =\{\text { On - street parking, Off - street parking lot, shared parking space }\}
\end{aligned}
$$

By using the nature that the difference between the probability variables of two independent double exponential distributions obeys the logistics distribution, the formula of Multinomial Logit (ML) model is as follows ${ }^{[13]}$ :

$$
P_{i n}=\frac{e^{V_{i n}}}{\sum_{j \in A_{n}} e^{V_{j n}}}
$$

Based on the above analysis of the influencing factors of residents' choices of shared parking spaces, parking rates $(F)$, walking distance after parking $(W d)$, parking information $(P I)$, and convenience of parking lots $(C)$ can be regarded as the selection limbs, and the function model of selection effect of on-street parking (on), off-street parking lot (off), and shared parking spaces (sh) is shown in the following formula:

$$
\begin{aligned}
& V_{\text {on }}=\theta_{1} F_{\text {on }}+\theta_{2} W d_{\text {on }}+\theta_{3} P I_{\text {on }}+\theta_{4} C_{\text {on }}+\beta_{1} \\
& V_{\text {off }}=\theta_{1} F_{\text {off }}+\theta_{2} W d_{\text {off }}+\theta_{3} P I_{\text {off }}+\theta_{4} C_{\text {off }}+\beta_{2} \\
& V_{\text {sh }}=\theta_{1} F_{\text {sh }}+\theta_{2} W d_{\text {sh }}+\theta_{3} P I_{\text {sh }}+\theta_{4} C_{\text {sh }}+\beta_{3}
\end{aligned}
$$

Wherein, $V$ is the utility function, $\theta_{n}$ is an unknown parameter variable, and $\beta_{n}$ is an intrinsic dummy variable $\mathrm{e}^{[14]}$.

\section{Application Examples}

Gulou District is located in the northwest of Nanjing's main urban area, and the whole district covers an administrative area of 26.62 square kilometres, with a population of 826,400 and a population density of 33,500 people / km2. According to statistics, the number of small cars in Gulou District on hand is 124,000, and the density of cars reaches 4,654 / km2. However, the planning and construction of parking facilities in Gulou District have not received enough attention, and the contradiction between supply and demand for parking is rather prominent.

This paper conducts a survey of intention of shared parking spaces to residents in Gulou District, uses MATLAB software to build a model and calibrate and test parameters, the hit rate of the model $\mathrm{R}=90.4 \%$, and the accuracy of the model is relatively high. The analysis results are shown in Table 1: 
Table 1. Calibration Results of Parameters of Logit Model.

\begin{tabular}{c|c|c|c|c}
\hline \multirow{2}{*}{ Variable type } & Variable name & $\begin{array}{c}\text { Estimated } \\
\text { parameter } \\
\text { value }\end{array}$ & $\begin{array}{c}\text { Standard } \\
\text { error }\end{array}$ & $\begin{array}{c}\text { T- test } \\
\text { value }\end{array}$ \\
\hline \multirow{4}{*}{\begin{tabular}{c} 
Constant term \\
\cline { 1 - 4 }
\end{tabular}} & On-street parking constant $\beta_{1}$ & 1.98 & 0.834 & 4.08 \\
\cline { 2 - 5 } & Off-street parking constant $\beta_{2}$ & 3.50 & 0.810 & 4.79 \\
\cline { 2 - 5 } $\begin{array}{c}\text { Parking } \\
\text { attribute }\end{array}$ & Shared parking constant $\beta_{3}$ & -5.47 & 0.183 & -5.69 \\
\cline { 2 - 5 } & Palking distance after parking $\theta_{2}$ & -0.931 & 0.579 & -2.61 \\
\cline { 2 - 5 } & Parking information $\theta_{3}$ & 0.769 & 0.018 & -2.29 \\
\cline { 2 - 5 } & Parking convenience $\theta_{4}$ & 1.27 & 0.429 & 2.44 \\
\hline \multirow{2}{*}{$\begin{array}{c}\text { Other test } \\
\text { values }\end{array}$} & $\rho^{2}$ & & 0.529 & \\
\cline { 2 - 5 } & $-\rho^{2}$ & & 0.437 & \\
\hline
\end{tabular}

According to the above results, the calibrated parameters are tested and analyzed.

(1) In the calibration result of parking attribute: the coefficients of the terms of parking rates and walking distance after parking are negative, that is, parking rates and walking distance after parking have a negative effect on the choices of shared parking spaces; the coefficients of parking information and parking convenience are both positive values, that is, parking information and parking convenience exert a positive effect on residents' choices of shared parking spaces.

(2) Evaluation of parameter significance. The confidence coefficient of this model is $\alpha=0.10$, in which the absolute value of t-test for each parameter calibrated is greater than 1.96, therefore it is judged that the model has a very high significance, and it is 90 percent sure that such factors as parking rate, walking distance after parking, parking information, and parking convenience and other factors exert a significant impact on the choices of shared parking spaces.

(3) McFadden determines that the coefficients $\rho^{2}$ and $-\rho^{2}$ are both greater than 0.3 , and the hit rate of the model $\mathrm{R}$ is larger than $80 \%$, so the model has a relatively high accuracy and can accurately predict the residents' demand for shared parking spaces.

\section{Conclusions}

This paper discusses urban residents' choice behaviors of shared parking spaces, and analyzes the influence of factors such as parking rate, walking distance after parking, parking information and convenience of parking lots on the choices of shared spaces. Moreover, by taking Gulou District, Nanjing City as an example, it builds a Logit model for discrete choices of shared parking spaces. Upon examination, the model has relatively high accuracy and can effectively predict urban residents' choices of shared parking spaces, providing theoretical basis for further research on the number of shared parking spaces open to the outside in urban residential areas. This paper assumes that the residents' acceptance of shared parking spaces is not different from that of ordinary parking lots, while parkers still have some concerns in making parking decisions. In future research, it is still necessary to focus on analyzing the impact of acceptance of shared parking spaces on parkers' choice behaviors. 


\section{Acknowledgements}

The research work described in this paper is supported by Anhui Provincial Quality Engineering Project Transportation Engineering Excellence Engineer Training Plan (2016zjjh054) and Hohai University Wentian College scientific research project "Research on Urban Parking Sharing Berth Demand” (WT17002ZD).

\section{References}

[1] Chen, Y., Guo, X. and Ran, J. (2010) The Shared Parking Facilities to the Building in Cities. Modern Urban Research, 25, 21-25.

[2] N. Lalani. (1984) Evaluating Shared Parking for New Developments. Public Works, 115, 123.

[3] Iman. (2006) Applying Shared-Parking Turn-Time (SPATT) Model and Geographic Information System in the Supply And Demand Analysis of Parking Space. 57.

[4] Ran, J., Guo, X., Tang, L. and Zhang, Y. (2011) Bi-Level Model for Shared Parking Decision-Making Based On Parking Lot Assignment Simulation. Journal of Southeast University (English Edition), 27, 322-327.

[5] Pan, C., Zhao, S., Yao, R. (2012) Variation Analysis of Parking Behaviours with Different Travel Purposes. Computer and Communications, 30, 39-42.

[6] Guan, H. and Yao, S. (2005) A Choice Model of the Length of Parking Time in CBD. Journal of Highway and Transportation Research and Development, 11, 148-150.

[7] Zong, F., Zhang, H. and Z. Juan. (2010) Bayesian Network-Based Parking Behaviour Analysis Systems. Engineering-Theory \& Practice, 30, 948-955.

[8] Mo, Y. and Yan, K. (2007) Analysis of the Performance of The Pgis in Metropolitan Area. Road Traffic \& Safety, 7, 33-36.

[9] Guan, H. and Liu, X. (2003) Parking Plan Design and Management (Communications Press, China).

[10] Feng, S. and Wang, B. (2015) Method for Parking Demand Forecasting Based on Parking Space Sharing. Shanxi Architecture, 41(32), 1-3.

[11] Xie, R., Qiu, Z. and Li, Q. (2006) Application of Logit Model in Estimating the Distribution Rate of Passenger Flows on Guangzhou-Shenzhen Railway. China Railway Science, 27(3), 111-113.

[12] Han, X. and Wang, D. (2017) Passenger Flow Distribution Model under the Interruption of Urban Rail Transit Network. Lecture Notes in Electrical Engineering, 419, 211-221.

[13] Li, Q. (2011) The Shared Parking Demand Forecast of Urban Multi-Functional Building. Technology \& Economy in Areas of Communications, 13(6), 61-63.

[14] Wang, Y. (2016) A Study of Shared Parking for Urban Complex. Journal of Transport Information and Safety, 34(2), 123-128. 